\title{
Long-term efficacy and downstream mechanism of anti-annexinA2 monoclonal antibody (anti-ANX A2 mAb) in a pre-clinical model of aggressive human breast cancer
}

Mahesh C. Sharma, ${ }^{1,2 *}$ George P. Tuszynski, ${ }^{4}$ Marc R. Blackman ${ }^{1.2,3}$ and Meena Sharma ${ }^{5}$

${ }^{1}$ Research Service, Veterans Affairs Medical Center, Washington DC 20422, ${ }^{2,3}$ Departments of Biochemistry and Molecular Medicine and Medicine, George Washington University, Washington, DC., ${ }^{4}$ Department of Neuroscience, Temple University School of Medicine, Philadelphia, PA $19140,{ }^{5}$ University of Pennsylvania School of Medicine, Philadelphia, PA 19104,

\section{* Address correspondence to:}

Mahesh C. Sharma, PhD

Professor of Biochemistry and Molecular Medicine

Director, Laboratory of Geriatric Endocrinology and Metabolism

Research Service (151)

Veterans Affairs Medical Center

50 Irving Street, NW

Washington, DC 20422

Email: Mahesh.Sharma@va.gov 


\begin{abstract}
:
There is considerable direct evidence that calcium binding protein ANX A2 is a potential target for treating aggressive breast cancer. The most compelling data are based on the finding of ANX A2 overexpression in aggressive triple negative human breast cancer (TNBC) cell lines and in human breast cancer tissues. Previously, we and others reported a unique role of ANX A2 in cancer invasion, including breast cancer. Moreover, we demonstrated that anti-ANX A2 mAbmediated immunoneutralization of ANX A2 inhibited invasive human breast cancer growth in a xenograft model. We further evaluated the long-term effects of multiple treatments with antiANX A2 mAb and its mechanism of inhibition on human breast tumor growth. We now demonstrate that three treatments with anti-ANX A2 mAb led to significant inhibition of breast tumor growth in immunodeficient mice, and that the anti-tumor response was demonstrable from day 94. After treatment, we followed tumor growth for 172 days and demonstrated $67 \%$ inhibition of tumor growth without detectable adverse effects. Biochemical analysis demonstrated that anti-ANX A2 mAb treatment caused significant inhibition of conversion of tissue plasminogen activator (tPA) in the tumor microenvironment. This led to disruption of plasmin generation that consequently inhibited activation of MMP-9 and MMP-2. These results suggest that ANX A2 plays an important role in aggressive breast tumor growth by regulating proteolytic pathways in the tumor microenvironment. ANX A2 may represent a new target for the development of therapeutics for treatment of aggressive breast cancer.
\end{abstract}




\section{Introduction}

Triple Negative Breast Cancer (TNBC) patients are often diagnosed with invasive cancer and have a high probability of development of metastasis, which accounts for nearly a $90 \%$ mortality. Currently, Her-2 (ErbB-2), estrogen receptor (ER) and progesterone receptor (PR) are the most commonly used as targets/biomarkers used for the detection and/or treatment of breast cancer. Approximately 20-30\% of breast cancer patients do not express these biomarkers and are clinically diagnosed with TNBC and will most likely develop metastases. For decades, breast cancer treatment included surgery, radiation therapy, chemotherapy, and/or hormonal therapy. During the last 15 years, the FDA approved monoclonal antibody based therapy (Trastuzumab) was introduced based on overexpression of HER-2 receptors in breast cancer patients [1] . Trastuzumab proved to be very effective in the treatment of patients with HER-2 overexpressing breast cancer. Consequently, the scientific community and pharmaceutical companies have been keen to develop antibody based therapies not only for many cancers, but for other diseases as well. A principal reason is because antibodies are highly selective for their target and exert minimum side effects. The best example in this class is the FDA approval of Avastin (bevacizumab), a monoclonal antibody against VEGF. Bevacizumab is frequently used for the treatment of cancer [2-4].

During the last two decades remarkable progress has been made and many therapeutic options have been developed for the treatment of breast cancer, yet chemotherapy is given to almost all breast cancer patients despite the associated high toxicity and many side-effects that sometimes cause death. Of particular note is that, chemotherapy only benefits a small proportion of patients (5-10\%) [5], and its effects to slow metastasis and tumor growth is only temporary. Currently treatments to permanently eradicate invasive/metastatic breast cancer do not exist. Therefore, there is an urgent clinical need to identify reliable target(s)/biomarkers that will inform development of new therapeutic options for treatment of invasive breast cancer.

Our laboratory devoted more than a decade to detect novel TNBC-specific target(s)/biomarker(s). We recently identified specific expression of ANX A2 in aggressive human breast cancer cell lines, and observed overexpression of ANX A2 in breast cancer patients with invasive carcinoma [6]. Based on our observations and those of others, we believe that ANX A2 may be a potential biomarker to identify patients with aggressive breast cancer and could be used as a target for the treatment of breast cancer [7-9]. ANX A2 is a member of the ubiquitous Annexin protein family, which bind calcium and phospholipids and also are in vivo substrates for tyrosine kinase phosphorylation by pp60v ${ }^{\text {src }}$, protein kinase C (PKC) and EGFR [10-14]. ANX A2 exerts its multiple functions by binding to different intra and extracellular ligands such as tPA, $\mathrm{Ca}^{++}$and S100A10 [15-17]. These observations suggest that the protein plays an important role in signal transduction. Extracellular ANX A2 acts as a co-receptor for tPA and plasminogen, resulting in increased local plasmin generation [16, 18]. Plasmin has been reported to play a critical role in angiogenesis, tissue remodeling and tumor invasion and metastasis [19-23]. It is now well established that ANX A2 plays a critical role in tumor 
invasion and metastasis $[9,21,24,25]$. Based on the evidence from our laboratory and those of others, we quickly tested target validity of ANX A2 in a "proof of concept" study in immunodeficient mice bearing aggressive human breast tumors. We used anti-ANX A2mAb to disrupt ANX A2 function and demonstrated significant inhibition of human breast tumor growth in a mouse xenograft model [26]. Inhibition of tumor growth was due to inhibition of tumor neoangiogenesis. In the present study, we extended our observation to further evaluate longterm effects of multiple treatments of anti-ANX A2 mAb in immunodeficient mice bearing human breast tumors. Moreover, we also investigated the potential downstream mechanism(s) of inhibition of neoangiogenesis. Here we report that multiple treatments with anti-ANX A2 mAb nearly completely inhibited conversion of active tPA in the tumor microenvironment. Lack of active tPA failed to elicit plasminogen to plasmin activation in the tumor. The downstream effect of this biochemical pathway was inhibition of activation of matrix metalloproteinases (MMP-9 and MMP-2). Consequently, accumulation of excess, inactive latent MMP-9/2 was observed in the tumor microenvironment. These findings suggest that ANX A2 is a multifunctional modulator of neoangiogenesis, presumably, via targeting the tPA-plasmin-MMP-2/9 axis and hence, ANX A2 represents a potentially new target for the development of anti-cancer strategies for aggressive human breast cancer.

\section{Materials and Methods}

Human lys-plasminogen, plasmin and recombinant tPA were purchased from Calbiochem, (La Jolla, CA). Electrophoresis reagents were procured from BioRad, (Richmond, CA). Anti-tPA monoclonal antibodies were purchased from American Diagnostica (Stanford, CT). Anti MMP-2 and MMP-9 antibodies were purchased from Oncogene Sciences (Cambridge, MA). Antibodies to ANX A2 were generated in our laboratory [6]. ECL kit was purchased from Thermo-Fisher (Waltham, MA). Chromozyme PL was purchased from Roche Molecular Biochemicals (Indianapolis, IN). Cell culture regents were purchased from (Mediatech, Inc. Manassas, VA). All other chemicals used in this study were of analytical grade.

Cell culture and maintenance: The invasive human breast cancer MDA-MB231 cell line was provided by Dr. George Tuszynski, (Temple University Philadelphia, PA). MDA-MB231 cells were grown in RPMI 1640 media containing 10\% fetal calf serum (FCS) supplemented with Lglutamine and antibiotics according to our established method [25].

Mouse model of human breast cancer: All animal experiments were performed on 4-6-weekold intact female nude mice purchased from the National Cancer Institute, Frederick, MD. Mice were acclimated to the animal facility for one week prior to study. Studies involving animals were conducted in accordance with a code of practice established by the Veterans Affairs Medical Center's R\&D and Institutional Animal Care and Use (IACUC) committees. Human breast cancer MDA-MB231 cells have been characterized in our laboratory for overexpression of ANX A2, and tPA $[25,27]$. MDA-MB231 cells were implanted $\left(1 \times 10^{6}\right.$ cells in $\left.0.1 \mathrm{ml}\right)$ in the hind flank of the nude mice $(n=14)$, as we and other reported earlier $[6,28]$. When tumor volume was approximately $30-50 \mathrm{~mm}^{3}$, mice were randomly divided into two groups $(\mathrm{n}=7$ in each group). 
One group of mice was injected with anti-ANX A2 mAb (three treatments of $10 \mathrm{mg} / \mathrm{kg}$ body weight in $0.1 \mathrm{ml}$, see table- 1 for detail). The control group of mice was injected with equal amounts of isotype matched mouse IgG via tail veins. Tumor growth was measured using a digital caliper and tumor volume was calculated using the formula (length $\times$ width ${ }^{2} \times 0.52$ ) as reported previously [6]. Animals' weights were recorded during the study. At the end of the experiment, mice were sacrificed and the ratio of treated tumor volume was determined for the last time point. Tumors were photographed, harvested and snap frozen in $-80^{\circ} \mathrm{c}$ for further analyses.

Immunoblot analysis: Tumor tissues were homogenized in PBS containing a cocktail of protease inhibitors. Protein concentration was measured using Bradford assay (Bio-Rad

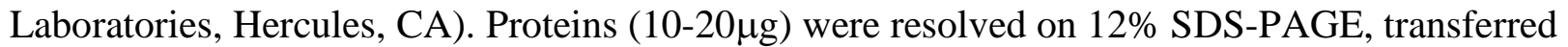
to nitrocellulose membrane, incubated with corresponding primary antibodies followed by secondary antibodies conjugated with horseradish peroxidase (HRP). Membrane was developed using the ECL kit according to our established procedure [6, 25, 29]

Plasmin generation in the tumor microenvironment: Pieces of tumor tissues were excised and homogenized in chilled PBS without protease inhibitors and used for endogenous plasmin generation assay, in the tumor with minor modifications, as described previously [26, 30]. Briefly, to determine tumor derived activation of plasminogen, ten $\mu \mathrm{g}$ of protein was incubated with plasminogen $(2 \mu \mathrm{M}$ final concentration), and plasmin-specific chromogenic substrate chromozyme PL $(2 \mathrm{mM})$ in a total volume of $100 \mu \mathrm{l}$ in a 96-wells plate. Reaction mixtures were incubated for 30 minutes [6, 20]. The change in color was measured at $405 \mathrm{~nm}$ using a spectrophotometer, which serves as a direct measure of plasminogen activation to plasmin formation. Appropriate controls were included in this experiment to determine non-specific plasmin generation. Control well \#1 was designed to assess self-degradation of plasminogen to plasmin by incubating plasminogen with chromogenic substrate chromozyme PL. Control well \#2 was included to assess any plasmin activity in tissues by directly incubating tumor tissues with Chromozyme PL. Non-specific plasmin generated in these wells was subtracted to calculate tumor specific plasmin generation.

\section{Results}

Multiple treatments of anti-ANX A2 mAb demonstrated tumor static response against aggressive human breast cancer for the long-term:

Previously, we observed over expression of ANX A2 on the surface of aggressive human breast cancer cells [26]. Moreover, we and others have demonstrated that ANX A2 is required for breast cancer cell invasion and migration [9, 24-26, 31]. In a "proof of concept" experiment we demonstrated that anti-ANX A2 mAb treatment of immunodeficient mice $(10 \mathrm{mg} / \mathrm{kg} \quad$ b.w $)$ bearing aggressive human breast tumors

\begin{tabular}{|l|l|l|l|l|l|l|}
\hline $\begin{array}{l}\text { Human breast } \\
\text { cancer cell lines }\end{array}$ & $\mathbf{n}$ & $\begin{array}{l}\text { Treatment } \\
\text { (Control) }\end{array}$ & $\mathbf{n}$ & $\begin{array}{l}\text { Treatment } \\
\text { (Experimental) }\end{array}$ & $\begin{array}{l}\text { Dose } \\
\text { (mg/ } \\
\mathbf{k g})\end{array}$ & $\begin{array}{l}\text { Days } \\
\text { treatment } \\
\text { injected }\end{array}$ \\
\hline MDA-MB231 & 7 & $\begin{array}{l}\text { Isotype matched } \\
\text { IgG }\end{array}$ & 7 & $\begin{array}{l}\text { Anti- } \\
\text { ANXA2mAb }\end{array}$ & 10 & 0day \\
\hline MDA-MB231 & $\begin{array}{lll}\text { Isotype matched } \\
\text { IgG }\end{array}$ & $\begin{array}{l}\text { Anti- } \\
\text { ANXA2mAb }\end{array}$ & 10 & $20^{\text {th }}$ day \\
\hline MDA-MB231 & $\begin{array}{lll}\text { Isotype matched } \\
\text { IgG }\end{array}$ & $\begin{array}{l}\text { Anti- } \\
\text { ANXA2mAb }\end{array}$ & 10 & $84^{\text {th }}$ day \\
\hline
\end{tabular}
(MDA-MB231 cells) exhibited anti-breast tumor activity [26]. For the first time, these in vivo data indicated ANX A2 as a potential target for treatment of invasive breast tumors. These 
observations prompted us to investigate the long-term efficacy of multiple treatments of antiANX A2 mAb in immunodeficient mice bearing aggressive human breast tumors. Anti-ANX A2 $\mathrm{mAb}$ was administered as shown in the table below and tumor growth patterns were followed up to 172 days (Fig.1A and B). We also investigated the anti-ANX A2mAb-mediated downstream mechanism of inhibition of breast tumor growth. Consistent with our previous results, multiple treatments with anti-ANX A2mAb led to substantial inhibition of tumor growth for up to 172 days whereas control (IgG treated) mice exhibited exponential tumor growth (Fig.1A and B). Interestingly, data analysis of tumor growth indicated significant inhibition of tumor growth beginning at day 94 , which is only two weeks after $3^{\text {rd }}$ treatment $(p>0.05)$.

In fact, breast tumor growth in control animals was so great that mice were unable to walk; therefore, we discontinued our experiment on $172^{\text {nd }}$ day for the welfare of the animals. In this experiment, we observed that in some animals human breast tumors regressed to microscopic dormant foci, and tumors in two mice were unable to grow until the end of the experiment (Fig.1D). However, in other animals antibody treatments elicited a robust effect but not as good as in the two animals described above. These results indicated that anti-A2mAb treatment acted differently in individual mice (Fig1D) and may be due to differences in the tumor microenvironment of individual mice. These results suggest that long-term treatment with ANX A2mAb may be required to achieve complete inhibition of breast tumor growth. No visible toxicity was noted during treatment, as all mice attained patterns of normal body weight (Fig.1C).

\section{Anti-ANX A2mAb inhibited tPA conversion in the human breast tumor microenvironment:}

tPA is a well-known ligand for cell surface ANX A2 [16, 27]. We demonstrated that in the aggressive xenograft breast tumor environment, ANX A2 organizes assembly of tPA and plasminogen for catalytic activation of plasminogen to plasmin [27, 32]. For the first time, we identified that anti-ANX A2 mAb treatments inhibited conversion of tPA to active forms in the tumor microenvironment (Fig.2A). The physiological role of plasmin is to digest the fibrin network of the blood clot to form soluble products. Plasmin has been shown to play an important role in breast tumor invasion and metastasis [19, 33].

tPA is a glycosylated serine protease which is synthesized as a single chain (sc-tPA) of about $65 \mathrm{kDa}$. Plasmin cleaves Arg (aa275-Ile) bond in sc-tPA to produce enzymatically highly active two chain tPA (tc-tPA) linked by a disulfide bond [34]. Interestingly, plasmin-mediated production of active tc-tPA suggests positive feedback regulation of tPA activity. Thus we investigated tPA and its mediated plasmin production in the tumor microenvironment. Consistent with observations by Wallen and colleagues, we also found three species of tPA in the breast tumor tissues, heavy chain and a light chain of active tPA with a fragment of lower molecular weight. Lower molecular weight band may be a proteolytic degradation product which has been found in glioblastoma tumors [35]. Anti-ANX A2mAb treatment almost completely inhibited activated tc-tPA, but had no apparent effect on a lower molecular weight protein (Fig.2A). Next, we investigated functional enzymatic activity of tPA in the tumors by determining plasminogen activation. Our results demonstrated an almost complete inhibition of plasminogen activation, most likely due to the unavailability of active tPA for this catalytic activation (Fig.2B and C).

Multiple treatments of anti-ANX A2mAb inhibited activation of matrix metalloproteinases (MMP-2 and MMP-9): Matrix metalloproteinases (MMPs) are a family of proteolytic enzymes 
that have been functionally linked with tissue remodeling and degradation of ECM and BM proteins [36]. Up-regulation of MMPs is well-established in breast cancer in vitro and in patients [37]. Because of the unique role of MMPs in angiogenesis, cancer invasion and metastasis, direct inhibitors of MMPs have been designed and tested in preclinical and clinical models for anticancer activities. Unexpectedly, MMP inhibitors yielded disappointing results triggering musculoskeletal toxicity [38]. We observed that anti-ANX A2 mAb treatment significantly inhibited activation of MMP-9 and MMP-2 (Fig.3A and B). Conversely, control (IgG treated) animals exhibited strong activation of pro-MMPs to active enzymes MMP-9/2. These findings suggest a previously unknown role of ANX A2 in MMP regulation [36]. Since plasmin is a wellknown activator of MMPs [36, 38], it is likely that anti-ANX A2 mAb mediated disruption of plasmin generation caused inhibition of MMP activation. Plasmin and activated MMP-9/2 both are known to degrade ECM and BM which facilitate neoangiogenesis activities in the tumor microenvironment [39-42]. Neoangiogenesis is a pre-requisite for breast tumor growth, invasion and metastasis [43-45]. Of note, in contrast to MMP inhibitors, anti-ANX A2mAb treatment was safe and effective and elicited no visible toxicity or death of animals. During our long-term antiANX A2mAb treatment, animals gained weight normally and maintained normal activity comparable to control animals.

\section{Discussion:}

In our previous studies, we identified ANX A2 as a potential target for the treatment of aggressive breast cancer and suggested that disruption of ANX A2 functions inhibits neoangiogenesis in vitro and in vivo in a xenograft model of human breast cancer [26]. These observations, and others, indicated that ANX A2 may be a potential therapeutic target for the treatment of aggressive breast cancer [9, 24, 46]. In this report we extended our observations and further investigated long-term efficacy of systemic administration of multi-dose anti-ANX $\mathrm{A} 2 \mathrm{mAb}$ treatment against aggressive human breast cancer in immunodeficient mice. We also evaluated anti-ANX A2-mediated potential downstream mechanisms of inhibition of aggressive breast tumor growth.

Our results revealed that anti-ANX A2mAb inhibited human breast carcinoma growth by $67 \%$ (Fig.1B). Data analysis demonstrated significant inhibition of tumor growth beginning at day 94, or about two weeks after the third treatment. Additional analyses from individual mice indicated almost complete regression (100\%) of tumor growth in two animals (Fig.1A).These two mice remained tumor free until the end of experiment (Fig.1D). Of the remaining five, one animal died and four exhibited continuous decline of tumor mass after discontinuation of antibody treatment (Fig.1D). Of note, human breast tumors in nude mice did not resume growth after cessation of therapy. There was no weight loss or other toxicity observed in any treated animals (Fig.1C) as mice maintained normal activity and strength. There was no evidence of bleeding or growth abnormalities. This apparent lack of toxicity emphasizes the importance of ANX A2 and generated significant interest to evaluate the downstream mechanism of anti-ANX A2 mAb's action.

Previously, we and others showed that ANX A2 is required for sprouting of new blood vessels, and suggested a critical role of ANX A2 in angiogenesis. Moreover, reports from our laboratory and those of others have confirmed involvement of ANX A2 in neoangiogenesis in the human breast tumor microenvironment, thereby facilitating tumor cell invasion and migration $[9,24,31]$. It has been shown that disruption of ANX A2 either by anti-ANX A2 or by peptides inhibits the angiogenic process possibly leading to inhibition of human breast tumor growth. 
ANX A2 is a major receptor for tPA and plasminogen. ANX A2 organizes assembly of tPA and plasminogen on the cell surface for efficient biochemical activation of plasminogen to plasmin [16]. We assessed this biochemical pathway in breast tumor tissues harvested from immunodeficient mice. Our findings suggested that anti-ANXA2mAb-mediated immunoneutralization of ANX A2 inhibited conversion of active tc-tPA in the tumor microenvironment (Fig.2A).

These observations are highly significant, as previously Jessani and colleagues (2004) noted that MDA-MB231 cells implanted in the orthotropic mammary fat pad (m.f.p) environment accelerated synthesis of tPA in the m.f.p microenvironment [47, 48]. These data were further validated by a clinical case report where tPA was identified as single major factor associated with breast cancer metastasis [49], and by previous clinical findings showing high levels of tPA in plasma of breast cancer patients [50]. Moreover, the maximal concentration of tumor tPA was found during early stages of breast carcinoma [51]. It has also been reported that insulin-like growth factor-1 (IGF-1) is required for tPA upregulation in breast cancer metastases [52]. Selective expression of tPA has been demonstrated in human pancreatic ductal adenocarcinoma (PDA) and contributes to tumor progression [53]. Collectively, these reports not only support our current observations, but also indicate involvement of tPA in plasminogen activation in the breast tumor microenvironment, thus contributing to breast tumor growth and metastasis. Therefore, we investigated endogenous activation of plasminogen in these xenografted human breast tumor tissues. As expected, anti-ANX A2mAb treatment resulted in significant inhibition of plasmin generation in breast tumor tissues (Fig.2 B and C). It is likely that inhibition of plasmin generation is due to unavailability of local, active tc-tPA. Excessive plasmin generation has been reported to play an important role in breast cancer invasion and metastasis[19, 54-56]. Clinical evidence suggests that uPA, an enzyme that also activates plasminogen, is a strong predictor of poor outcome in breast cancer patients [57-59] further suggesting the clinical importance of PA-plasmin system in aggressive breast cancer[19].

Plasmin is a strong serine protease, and is a powerful pro-inflammatory cell activator [60, 61] that is required for degradation of ECM and BM proteins to facilitate tissue repair and remodeling [61, 62]. The role of plasmin in BM degradation and infiltration of stroma by breast tumor cells has been reported [19]. During ECM degradation, matrix bound growth factors such as VEGF and inactive pro-MMPs are liberated and participate in the tissue remodeling process by activating the "angiogenic switch" [42, 63-66]. The catalytic manifestations of pro-MMPs are highly regulated and plasmin plays an important role in proteolytic processing of pro-MMPs to their functionally active form [62, 67-69]. Thus, active MMPs, specifically MMP-9 and MMP-2, trigger neoangiogenesis and facilitate tissue remodeling by degrading connective tissue, ECM, epithelial, endothelial cell basement membranes [38, 42, 62-66]. This MMP-mediated tissue degradation is a hallmark of tumor cell invasion and neoangiogenesis [39, 69-71]. Numerous investigators have reported involvement of the active form of MMP-9/2 in breast cancer neoangiogenesis and invasion [37, 64, 70, 72, 73].

Because plasmin is shown to activate pro-MMP-2/9 [67, 69, 74], we investigated the antiANX A2 mAb-mediated effects on MMP activation in human xenograft breast tumor tissues. Control animals produce plasmin efficiently in the tumor microenvironment show intense activation of MMP-2 and MMP-9 (Fig.3A, B). In contrast, animals bearing invasive human breast tumor treated with anti-ANX A2 mAb exhibited significant inhibition of both plasmin generation and MMP-2/9 activation (Figs. 2B., 3 A,B). Analysis of enzymes by immunoblot clearly showed accumulation of inactive enzyme pro-MMP-2/9 after anti-ANX A2mAb 
treatments (Fig. 3 A,B) suggesting that the concentration of plasmin in the tumor microenvironment is critical for MMP-9/2 activation for biological functions [67]. Previously, it has been reported that MMP-9/2 plays an important role in breast cancer invasion and metastasis, possibly due to induction of neoangiogenesis [75, 76]. Indeed, the $1562 \mathrm{~T}$ allele of MMP-9 and 735C allele of MMP-2 have been shown to be risk factors for breast cancer patients[77]. Consistent with the observations, a study of 270 breast cancer patients demonstrated overexpression of MMP-9/2 with a prognosis for shorter relapse free survival [78].

We and others have previously shown that ANX A2 regulates neoangiogenesis and plays an important role in human breast tumor growth, invasion and metastasis [26, 79-81]. Before our report, clinical studies had demonstrated that neoangiogenesis is a significant and independent prognostic indicator in patients with early stage invasive breast cancer [44, 45], suggesting a common link between ANX A2, neoangiogenesis and invasive breast cancer. Thus, it is likely that the substantial inhibition of aggressive human breast tumor growth by anti-ANX A2 mAb treatment is due to inhibition of plasmin-mediated regulation of MMP-9/2 activation. Our observations are consistent with clinical findings wherein both MMP-9 and MMP-2 have been implicated in aggressive breast tumor growth and have been suggested to be significant prognostic indicators of invasive carcinoma and risk factors for breast cancer [37, 64, 72, 77]. Of particular note, MMP-9 is highly expressed in triple negative breast cancer [82] and is associated with distant metastases with shorter progression free survival and overall survival (OS) in patients $[83,84]$. Activated forms of MMP-9 are frequently detected in invasive breast cancer patients [75] and correlated with shorter OS. Higher activation rates of MMP-9/2 were also observed in ovarian cancer patients with metastatic potential [71]. Consistent with the above clinical observations, we also observed a more robust inhibitory effect of anti-ANX A2mAb on MMP-9 versus MMP-2 activation in human breast tumors. It is possible that in the tumor microenvironment ANX A2 triggers a chain of biochemical events resulting in enzyme activation. This may provide a feedback mechanism for accelerated degradation of ECM and BM and potentially can initiate angiogenesis thereby aid aggressive tumor growth.

Taken together, our observations and those of suggest that anti-ANX A2 mAb treatment mediated inhibition of tPA conversion triggered a negative feedback leading to inhibition of plasmin generation in the breast tumor microenvironment. This inhibition of plasmin in turn blocks MMP-9/2 activation, thereby inhibiting ECM and BM degradation, and leading to disruption of neoangiogenesis in the tumor microenvironment. It is likely that disruption of the aforementioned tPA-ANX A2-mediated biochemical cascade resulted in inhibition of invasive breast tumor growth in our immunodeficient mice. Our findings were further supported by a recent in vivo study where anti-ANX A2mAb treatment inhibited PDA tumor growth, invasion and metastasis. Moreover, anti-ANX A2mAb treatment significantly increased survival of the PDA tumor bearing mice [85]. Our observations are significant, considering the fact that despite multiple clinical and experimental studies identifying MMP-9/2 as potential targets for aggressive breast cancer, direct inhibitors of MMPs in clinical trials have proven unsuccessful due to considerable musculoskeletal toxicity. The latter disappointing results forced clinicians to halt clinical trials $[38,39,86,87]$. In this context, our present findings offer a possibility of indirect endogenous inhibition of MMP-9/2 activation by disrupting biochemical events which are activated in invasive breast cancer and required for MMP-9/2 activation. It is possible that indirect inhibitors of MMP-9/2 activation may be less toxic because they will selectively inhibit tumor activated biochemical cascade which triggers MMP-9/2 activation, and not interfere with the physiological activity of MMP-9/2, Further investigation is warranted to determine whether 
this can serve as a relevant strategy for the development of therapeutics for many aggressive cancers including breast cancer.

5. Acknowledgments: This study was supported in part by the Research Service of the Veterans Affairs Medical Center, Washington DC and Department of Defense Idea award W81XWH-07-1-0424 and Department of Defense Concept award DAMD1703-1-0761 (MCS). We thank Maria Okolita and Dr. June Zhou for their assistance with animal handling and tail vein injections, respectively.

\section{References:}

[1] D.E. Milenic, Monoclonal antibody-based therapy strategies: providing options for the cancer patient, Curr Pharm Des, 8 (2002) 1749-1764.

[2] M.I. Braghiroli, J. Sabbaga, P.M. Hoff, Bevacizumab: overview of the literature, Expert Rev Anticancer Ther, 12 567-580.

[3] D.B. Jacoby, E. Dyskin, M. Yalcin, K. Kesavan, W. Dahlberg, J. Ratliff, E.W. Johnson, S.A. Mousa, Potent pleiotropic anti-angiogenic effects of TM601, a synthetic chlorotoxin peptide, Anticancer Res, 30 39-46.

[4] J.J. Vredenburgh, A. Desjardins, J.E. Herndon, 2nd, J.M. Dowell, D.A. Reardon, J.A. Quinn, J.N. Rich, S. Sathornsumetee, S. Gururangan, M. Wagner, D.D. Bigner, A.H. Friedman, H.S. Friedman, Phase II trial of bevacizumab and irinotecan in recurrent malignant glioma, Clin Cancer Res, 13 (2007) 1253-1259.

[5] M. Baum, Harms from breast cancer screening outweigh benefits if death caused by treatment is included, BMJ (Clinical research ed, $346 \mathrm{f} 385$.

[6] M.R. Sharma, V. Rothman, G.P. Tuszynski, M.C. Sharma, Antibody-directed targeting of angiostatin's receptor annexin II inhibits Lewis Lung Carcinoma tumor growth via blocking of plasminogen activation: possible biochemical mechanism of angiostatin's action, Exp Mol Pathol, 81 (2006) 136-145.

[7] P.K. Shetty, S.I. Thamake, S. Biswas, S.L. Johansson, J.K. Vishwanatha, Reciprocal regulation of annexin A2 and EGFR with Her-2 in Her-2 negative and herceptin-resistant breast cancer, PloS one, 7 e44299.

[8] M.C. Sharma, M. Sharma, The role of annexin II in angiogenesis and tumor progression: a potential therapeutic target, Curr Pharm Des, 13 (2007) 3568-3575.

[9] F. Zhang, L. Zhang, B. Zhang, X. Wei, Y. Yang, R.Z. Qi, G. Ying, N. Zhang, R. Niu, Anxa2 plays a critical role in enhanced invasiveness of the multidrug resistant human breast cancer cells, Journal of proteome research, 8 (2009) 5041-5047.

[10] E. Erikson, R.L. Erikson, Identification of a cellular protein substrate phosphorylated by the avian sarcoma virus-transforming gene product, Cell, 21 (1980) 829-836.

[11] K.L. Gould, J.R. Woodgett, C.M. Isacke, T. Hunter, The protein-tyrosine kinase substrate p36 is also a substrate for protein kinase $C$ in vitro and in vivo, Molecular and cellular biology, 6 (1986) 2738-2744.

[12] K. Radke, G.S. Martin, Transformation by Rous sarcoma virus: effects of src gene expression on the synthesis and phosphorylation of cellular polypeptides, Proceedings of the National Academy of Sciences of the United States of America, 76 (1979) 5212-5216. 
[13] J.R. Glenney, Jr., B.F. Tack, Amino-terminal sequence of p36 and associated p10: identification of the site of tyrosine phosphorylation and homology with S-100, Proceedings of the National Academy of Sciences of the United States of America, 82 (1985) 7884-7888.

[14] B.K. De, K.S. Misono, T.J. Lukas, B. Mroczkowski, S. Cohen, A calcium-dependent 35kilodalton substrate for epidermal growth factor receptor/kinase isolated from normal tissue, The Journal of biological chemistry, 261 (1986) 13784-13792.

[15] V. Gerke, S.E. Moss, Annexins: from structure to function, Physiological reviews, 82 (2002) 331-371.

[16] G.M. Cesarman, C.A. Guevara, K.A. Hajjar, An endothelial cell receptor for plasminogen/tissue plasminogen activator (t-PA). II. Annexin II-mediated enhancement of t-PAdependent plasminogen activation, J Biol Chem, 269 (1994) 21198-21203.

[17] N. Zobiack, U. Rescher, C. Ludwig, D. Zeuschner, V. Gerke, The annexin 2/S100A10 complex controls the distribution of transferrin receptor-containing recycling endosomes, Mol Biol Cell, 14 (2003) 4896-4908.

[18] K.A. Hajjar, S. Krishnan, Annexin II: a mediator of the plasmin/plasminogen activator system, Trends Cardiovasc Med, 9 (1999) 128-138.

[19] C. Clavel, G. Chavanel, P. Birembaut, Detection of the plasmin system in human mammary pathology using immunofluorescence, Cancer research, 46 (1986) 5743-5747.

[20] C. Brownstein, A.B. Deora, A.T. Jacovina, R. Weintraub, M. Gertler, K.M. Khan, D.J. Falcone, K.A. Hajjar, Annexin II mediates plasminogen-dependent matrix invasion by human monocytes: enhanced expression by macrophages, Blood, 103 (2004) 317-324.

[21] V.M. Diaz, M. Hurtado, T.M. Thomson, J. Reventos, R. Paciucci, Specific interaction of tissue-type plasminogen activator (t-PA) with annexin II on the membrane of pancreatic cancer cells activates plasminogen and promotes invasion in vitro, Gut, 53 (2004) 993-1000.

[22] M.S. Pepper, R. Montesano, Proteolytic balance and capillary morphogenesis, Cell Differ Dev, 32 (1990) 319-327.

[23] M.S. Pepper, R. Montesano, S.J. Mandriota, L. Orci, J.D. Vassalli, Angiogenesis: a paradigm for balanced extracellular proteolysis during cell migration and morphogenesis, Enzyme Protein, 49 (1996) 138-162.

[24] P. Zhao, W. Zhang, J. Tang, X.K. Ma, J.Y. Dai, Y. Li, J.L. Jiang, S.H. Zhang, Z.N. Chen, Annexin II promotes invasion and migration of human hepatocellular carcinoma cells in vitro via its interaction with HAb18G/CD147, Cancer Sci, 101 (2010) 387-395.

[25] M.R. Sharma, L. Koltowski, R.T. Ownbey, G.P. Tuszynski, M.C. Sharma, Angiogenesisassociated protein annexin II in breast cancer: selective expression in invasive breast cancer and contribution to tumor invasion and progression, Exp Mol Pathol, 81 (2006) 146-156.

[26] M. Sharma, M.R. Blackman, M.C. Sharma, Antibody-directed neutralization of annexin II (ANX II) inhibits neoangiogenesis and human breast tumor growth in a xenograft model, Exp Mol Pathol, 92 175-184.

[27] M. Sharma, R.T. Ownbey, M.C. Sharma, Breast cancer cell surface annexin II induces cell migration and neoangiogenesis via tPA dependent plasmin generation, Exp Mol Pathol, 88 278286.

[28] M.S. O'Reilly, L. Holmgren, C. Chen, J. Folkman, Angiostatin induces and sustains dormancy of human primary tumors in mice, Nature medicine, 2 (1996) 689-692.

[29] G.P. Tuszynski, M.R. Sharma, V.L. Rothman, M.C. Sharma, Angiostatin binds to tyrosine kinase substrate annexin II through the lysine-binding domain in endothelial cells, Microvasc Res, 64 (2002) 448-462. 
[30] M.J. Mulligan-Kehoe, R. Wagner, C. Wieland, R. Powell, A truncated plasminogen activator inhibitor-1 protein induces and inhibits angiostatin (kringles 1-3), a plasminogen cleavage product, J Biol Chem, 276 (2001) 8588-8596.

[31] J. Zhang, B. Guo, Y. Zhang, J. Cao, T. Chen, Silencing of the annexin II gene downregulates the levels of S100A10, c-Myc, and plasmin and inhibits breast cancer cell proliferation and invasion, Saudi Med J, 31 374-381.

[32] K.A. Hajjar, J.S. Menell, Annexin II: a novel mediator of cell surface plasmin generation, Ann N Y Acad Sci, 811 (1997) 337-349.

[33] M. Schmitt, N. Harbeck, C. Thomssen, O. Wilhelm, V. Magdolen, U. Reuning, K. Ulm, H. Hofler, F. Janicke, H. Graeff, Clinical impact of the plasminogen activation system in tumor invasion and metastasis: prognostic relevance and target for therapy, Thromb Haemost, 78 (1997) 285-296.

[34] P. Wallen, G. Pohl, N. Bergsdorf, M. Ranby, T. Ny, H. Jornvall, Purification and characterization of a melanoma cell plasminogen activator, European journal of biochemistry / FEBS, 132 (1983) 681-686.

[35] K.Y. Goh, W.S. Poon, D.T. Chan, C.P. Ip, Tissue plasminogen activator expression in meningiomas and glioblastomas, Clinical neurology and neurosurgery, 107 (2005) 296-300.

[36] T.H. Kim, W.M. Mars, D.B. Stolz, G.K. Michalopoulos, Expression and activation of proMMP-2 and pro-MMP-9 during rat liver regeneration, Hepatology, 31 (2000) 75-82.

[37] K.W. Min, D.H. Kim, S.I. Do, K. Kim, H.J. Lee, S.W. Chae, J.H. Sohn, J.S. Pyo, Y.H. Oh, W.S. Kim, S.Y. Lee, S. Oh, S.H. Choi, Y.L. Park, C.H. Park, Expression patterns of stromal MMP-2 and tumoural MMP-2 and -9 are significant prognostic factors in invasive ductal carcinoma of the breast, Apmis, 122 1196-1206.

[38] D. Belotti, P. Paganoni, R. Giavazzi, MMP inhibitors: experimental and clinical studies, The International journal of biological markers, 14 (1999) 232-238.

[39] S. Zucker, J. Cao, W.T. Chen, Critical appraisal of the use of matrix metalloproteinase inhibitors in cancer treatment, Oncogene, 19 (2000) 6642-6650.

[40] K. Bajou, L. Devy, V. Masson, V. Albert, F. Frankenne, A. Noel, J.M. Foidart, [Role of plasminogen activator inhibitor type 1 in tumor angiogenesis], Therapie, 56 (2001) 465-472.

[41] K. Bajou, V. Masson, R.D. Gerard, P.M. Schmitt, V. Albert, M. Praus, L.R. Lund, T.L. Frandsen, N. Brunner, K. Dano, N.E. Fusenig, U. Weidle, G. Carmeliet, D. Loskutoff, D. Collen, P. Carmeliet, J.M. Foidart, A. Noel, The plasminogen activator inhibitor PAI-1 controls in vivo tumor vascularization by interaction with proteases, not vitronectin. Implications for antiangiogenic strategies, J Cell Biol, 152 (2001) 777-784.

[42] N. Hiraoka, E. Allen, I.J. Apel, M.R. Gyetko, S.J. Weiss, Matrix metalloproteinases regulate neovascularization by acting as pericellular fibrinolysins, Cell, 95 (1998) 365-377.

[43] N. Weidner, J. Folkman, Tumoral vascularity as a prognostic factor in cancer, Important Adv Oncol, (1996) 167-190.

[44] N. Weidner, J. Folkman, F. Pozza, P. Bevilacqua, E.N. Allred, D.H. Moore, S. Meli, G. Gasparini, Tumor angiogenesis: a new significant and independent prognostic indicator in earlystage breast carcinoma, J Natl Cancer Inst, 84 (1992) 1875-1887.

[45] N. Weidner, J.P. Semple, W.R. Welch, J. Folkman, Tumor angiogenesis and metastasis-correlation in invasive breast carcinoma, N Engl J Med, 324 (1991) 1-8.

[46] B. Wu, F. Zhang, M. Yu, P. Zhao, W. Ji, H. Zhang, J. Han, R. Niu, Up-regulation of Anxa2 gene promotes proliferation and invasion of breast cancer MCF-7 cells, Cell proliferation, 45 189-198. 
[47] N. Jessani, M. Humphrey, W.H. McDonald, S. Niessen, K. Masuda, B. Gangadharan, J.R. Yates, 3rd, B.M. Mueller, B.F. Cravatt, Carcinoma and stromal enzyme activity profiles associated with breast tumor growth in vivo, Proc Natl Acad Sci U S A, 101 (2004) 1375613761.

[48] S.N. Nadim Jessani, Barbara M. Mueller, Benjamin F. Cravatt, Breast Cancer Cell Lines Grown in Vivo

What Goes in Isn't Always the Same as what Comes Out Cell Cycle, 4 (2005) 253-255.

[49] H.V. Naina, M.M. Patnaik, U.A. Ali, D. Chen, A.A. Ashrani, Systemic fibrinolysis caused by tissue plasminogen activator-producing metastatic breast cancer, J Clin Oncol, 28 e167-168.

[50] J. Grondahl-Hansen, F. Bach, P. Munkholm-Larsen, Tissue-type plasminogen activator in plasma from breast cancer patients determined by enzyme-linked immunosorbent assay, $\mathrm{Br} \mathbf{J}$ Cancer, 61 (1990) 412-414.

[51] C. Rella, M. Coviello, M. Quaranta, A. Paradiso, Tissue-type plasminogen activator as marker of functional steroid receptors in human breast cancer, Thromb Res, 69 (1993) 209-220.

[52] C.L. Chernicky, L. Yi, H. Tan, J. Ilan, Tissue-type plasminogen activator is upregulated in metastatic breast cancer cells exposed to insulin-like growth factor-I, Clin Breast Cancer, 6 (2005) 340-348.

[53] S. Aguilar, J.M. Corominas, N. Malats, J.A. Pereira, M. Dufresne, F.X. Real, P. Navarro, Tissue plasminogen activator in murine exocrine pancreas cancer: selective expression in ductal tumors and contribution to cancer progression, Am J Pathol, 165 (2004) 1129-1139.

[54] M.J. Duffy, P. O'Grady, D. Devaney, L. O'Siorain, J.J. Fennelly, H.J. Lijnen, Urokinaseplasminogen activator, a marker for aggressive breast carcinomas. Preliminary report, Cancer, 62 (1988) 531-533.

[55] E.S. Gershtein, N.E. Kushlinskii, [The clinical prospects for the study of the plasminogen activation system in breast cancer], Vestn Ross Akad Med Nauk, (1999) 58-61.

[56] M. Schmitt, F. Janicke, H. Graeff, Tumour-associated fibrinolysis: the prognostic relevance of plasminogen activators uPA and tPA in human breast cancer, Blood Coagul Fibrinolysis, 1 (1990) 695-702.

[57] F. Janicke, M. Schmitt, K. Ulm, W. Gossner, H. Graeff, Urokinase-type plasminogen activator antigen and early relapse in breast cancer, Lancet, 2 (1989) 1049.

[58] F. Janicke, A. Prechtl, C. Thomssen, N. Harbeck, C. Meisner, M. Untch, C.G. Sweep, H.K. Selbmann, H. Graeff, M. Schmitt, Randomized adjuvant chemotherapy trial in high-risk, lymph node-negative breast cancer patients identified by urokinase-type plasminogen activator and plasminogen activator inhibitor type 1, J Natl Cancer Inst, 93 (2001) 913-920.

[59] M.P. Look, W.L. van Putten, M.J. Duffy, N. Harbeck, I.J. Christensen, C. Thomssen, R. Kates, F. Spyratos, M. Ferno, S. Eppenberger-Castori, C.G. Sweep, K. Ulm, J.P. Peyrat, P.M. Martin, H. Magdelenat, N. Brunner, C. Duggan, B.W. Lisboa, P.O. Bendahl, V. Quillien, A. Daver, G. Ricolleau, M.E. Meijer-van Gelder, P. Manders, W.E. Fiets, M.A. Blankenstein, P. Broet, S. Romain, G. Daxenbichler, G. Windbichler, T. Cufer, S. Borstnar, W. Kueng, L.V. Beex, J.G. Klijn, N. O'Higgins, U. Eppenberger, F. Janicke, M. Schmitt, J.A. Foekens, Pooled analysis of prognostic impact of urokinase-type plasminogen activator and its inhibitor PAI-1 in 8377 breast cancer patients, J Natl Cancer Inst, 94 (2002) 116-128.

[60] T. Syrovets, M. Jendrach, A. Rohwedder, A. Schule, T. Simmet, Plasmin-induced expression of cytokines and tissue factor in human monocytes involves AP-1 and IKKbetamediated NF-kappaB activation, Blood, 97 (2001) 3941-3950. 
[61] M.S. Pepper, Extracellular proteolysis and angiogenesis, Thromb Haemost, 86 (2001) 346355.

[62] H.R. Lijnen, Plasmin and matrix metalloproteinases in vascular remodeling, Thromb Haemost, 86 (2001) 324-333.

[63] M.S. Pepper, Role of the matrix metalloproteinase and plasminogen activator-plasmin systems in angiogenesis, Arterioscler Thromb Vasc Biol, 21 (2001) 1104-1117.

[64] N. Peyri, M. Berard, F. Fauvel-Lafeve, V. Trochon, B. Arbeille, H. Lu, C. Legrand, M. Crepin, Breast tumor cells transendothelial migration induces endothelial cell anoikis through extracellular matrix degradation, Anticancer Res, 29 (2009) 2347-2355.

[65] X. Qian, T.N. Wang, V.L. Rothman, R.F. Nicosia, G.P. Tuszynski, Thrombospondin-1 modulates angiogenesis in vitro by up-regulation of matrix metalloproteinase-9 in endothelial cells, Exp Cell Res, 235 (1997) 403-412.

[66] Q.X. Sang, Complex role of matrix metalloproteinases in angiogenesis, Cell Res, 8 (1998) 171-177.

[67] E.N. Baramova, K. Bajou, A. Remacle, C. L'Hoir, H.W. Krell, U.H. Weidle, A. Noel, J.M. Foidart, Involvement of PA/plasmin system in the processing of pro-MMP-9 and in the second step of pro-MMP-2 activation, FEBS letters, 405 (1997) 157-162.

[68] S. Monea, K. Lehti, J. Keski-Oja, P. Mignatti, Plasmin activates pro-matrix metalloproteinase-2 with a membrane-type 1 matrix metalloproteinase-dependent mechanism, Journal of cellular physiology, 192 (2002) 160-170.

[69] N. Ramos-DeSimone, E. Hahn-Dantona, J. Sipley, H. Nagase, D.L. French, J.P. Quigley, Activation of matrix metalloproteinase-9 (MMP-9) via a converging plasmin/stromelysin-1 cascade enhances tumor cell invasion, J Biol Chem, 274 (1999) 13066-13076.

[70] J. Westermarck, V.M. Kahari, Regulation of matrix metalloproteinase expression in tumor invasion, Faseb J, 13 (1999) 781-792.

[71] B. Schmalfeldt, D. Prechtel, K. Harting, K. Spathe, S. Rutke, E. Konik, R. Fridman, U. Berger, M. Schmitt, W. Kuhn, E. Lengyel, Increased expression of matrix metalloproteinases (MMP)-2, MMP-9, and the urokinase-type plasminogen activator is associated with progression from benign to advanced ovarian cancer, Clin Cancer Res, 7 (2001) 2396-2404.

[72] D.C. Jinga, A. Blidaru, I. Condrea, C. Ardeleanu, C. Dragomir, G. Szegli, M. Stefanescu, C. Matache, MMP-9 and MMP-2 gelatinases and TIMP-1 and TIMP-2 inhibitors in breast cancer: correlations with prognostic factors, Journal of cellular and molecular medicine, 10 (2006) 499510.

[73] M. Egeblad, Z. Werb, New functions for the matrix metalloproteinases in cancer progression, Nat Rev Cancer, 2 (2002) 161-174.

[74] C. Tallant, A. Marrero, F.X. Gomis-Ruth, Matrix metalloproteinases: fold and function of their catalytic domains, Biochimica et biophysica acta, 1803 (2010) 20-28.

[75] B. Davies, D.W. Miles, L.C. Happerfield, M.S. Naylor, L.G. Bobrow, R.D. Rubens, F.R. Balkwill, Activity of type IV collagenases in benign and malignant breast disease, $\mathrm{Br} \mathrm{J}$ Cancer, 67 (1993) 1126-1131.

[76] L.J. van 't Veer, H. Dai, M.J. van de Vijver, Y.D. He, A.A. Hart, M. Mao, H.L. Peterse, K. van der Kooy, M.J. Marton, A.T. Witteveen, G.J. Schreiber, R.M. Kerkhoven, C. Roberts, P.S. Linsley, R. Bernards, S.H. Friend, Gene expression profiling predicts clinical outcome of breast cancer, Nature, 415 (2002) 530-536. 
[77] Z. Rahimi, K. Yari, Z. Rahimi, Matrix metalloproteinase-9 -1562T allele and its combination with MMP-2 -735 C allele are risk factors for breast cancer, Asian Pacific journal of cancer prevention : APJCP, 16 (2015) 1175-1179.

[78] E. Mylona, A. Nomikos, C. Magkou, M. Kamberou, I. Papassideri, A. Keramopoulos, L. Nakopoulou, The clinicopathological and prognostic significance of membrane type 1 matrix metalloproteinase (MT1-MMP) and MMP-9 according to their localization in invasive breast carcinoma, Histopathology, 50 (2007) 338-347.

[79] Q. Ling, A.T. Jacovina, A. Deora, M. Febbraio, R. Simantov, R.L. Silverstein, B. Hempstead, W.H. Mark, K.A. Hajjar, Annexin II regulates fibrin homeostasis and neoangiogenesis in vivo, The Journal of clinical investigation, 113 (2004) 38-48.

[80] A.M. Raddum, H. Hollas, I.A. Shumilin, P. Henklein, R. Kretsinger, T. Fossen, A. Vedeler, The native structure of annexin A2 peptides in hydrophilic environment determines their antiangiogenic effects, Biochemical pharmacology, 95 (2015) 1-15.

[81] A. Semov, M.J. Moreno, A. Onichtchenko, A. Abulrob, M. Ball, I. Ekiel, G. Pietrzynski, D. Stanimirovic, V. Alakhov, Metastasis-associated protein S100A4 induces angiogenesis through interaction with Annexin II and accelerated plasmin formation, J Biol Chem, 280 (2005) 2083320841.

[82] C. Mehner, A. Hockla, E. Miller, S. Ran, D.C. Radisky, E.S. Radisky, Tumor cell-produced matrix metalloproteinase 9 (MMP-9) drives malignant progression and metastasis of basal-like triple negative breast cancer, Oncotarget, 5 (2014) 2736-2749.

[83] L.O. Gonzalez, M.D. Corte, S. Junquera, R. Gonzalez-Fernandez, J.M. del Casar, C. Garcia, A. Andicoechea, J. Vazquez, R. Perez-Fernandez, F.J. Vizoso, Expression and prognostic significance of metalloproteases and their inhibitors in luminal A and basal-like phenotypes of breast carcinoma, Human pathology, 40 (2009) 1224-1233.

[84] S. Zhao, W. Ma, M. Zhang, D. Tang, Q. Shi, S. Xu, X. Zhang, Y. Liu, Y. Song, L. Liu, Q. Zhang, High expression of CD147 and MMP-9 is correlated with poor prognosis of triplenegative breast cancer (TNBC) patients, Medical oncology, 30 (2013) 335.

[85] L. Zheng, K. Foley, L. Huang, A. Leubner, G. Mo, K. Olino, B.H. Edil, M. Mizuma, R. Sharma, D.T. Le, R.A. Anders, P.B. Illei, J.E. Van Eyk, A. Maitra, D. Laheru, E.M. Jaffee, Tyrosine 23 phosphorylation-dependent cell-surface localization of annexin A2 is required for invasion and metastases of pancreatic cancer, PloS one, 6 e19390.

[86] L.M. Coussens, B. Fingleton, L.M. Matrisian, Matrix metalloproteinase inhibitors and cancer: trials and tribulations, Science (New York, N.Y, 295 (2002) 2387-2392.

[87] R.C. Figueira, L.R. Gomes, J.S. Neto, F.C. Silva, I.D. Silva, M.C. Sogayar, Correlation between MMPs and their inhibitors in breast cancer tumor tissue specimens and in cell lines with different metastatic potential, BMC Cancer, 9 (2009) 20. 
Fig.1 A
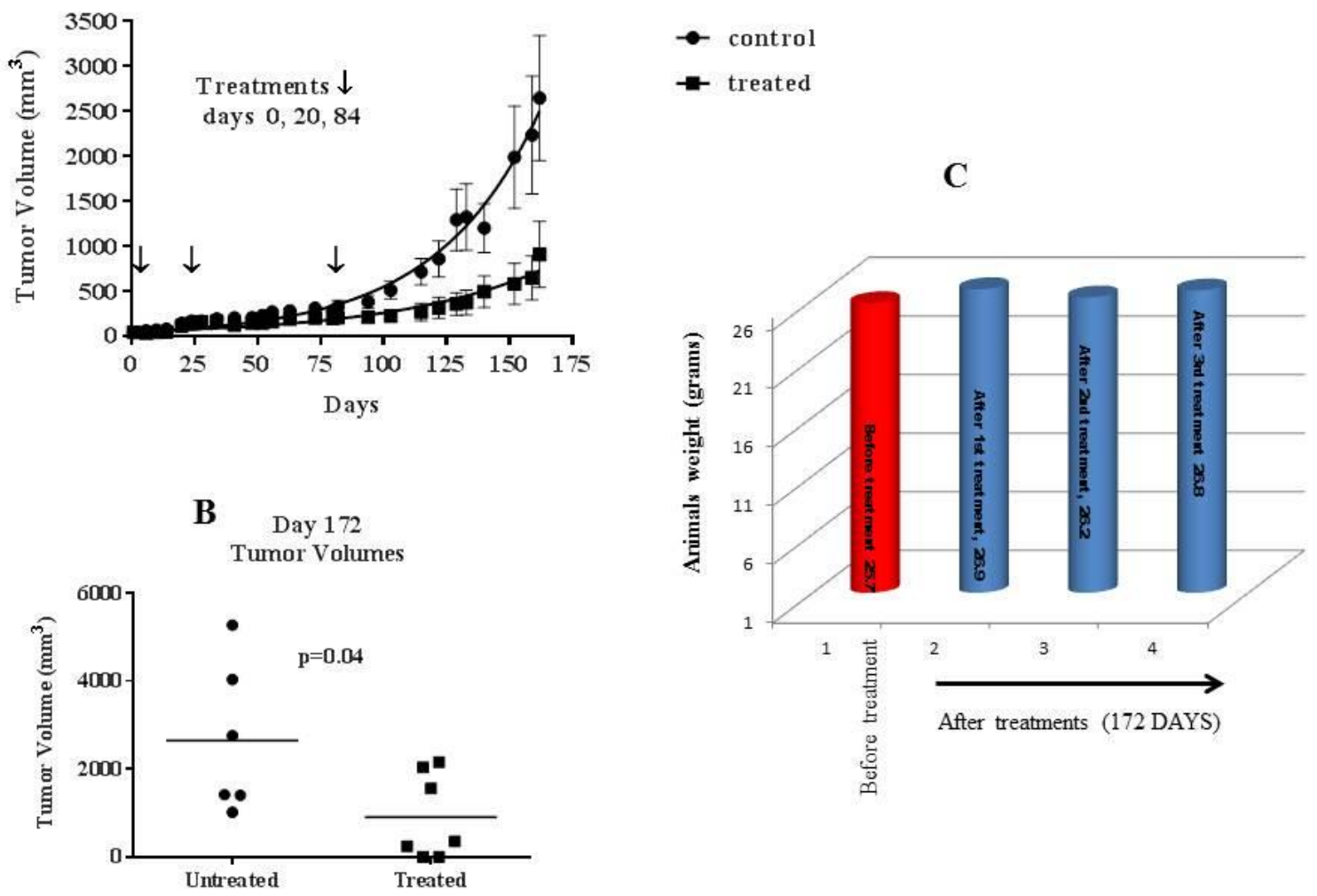
Fig.1D
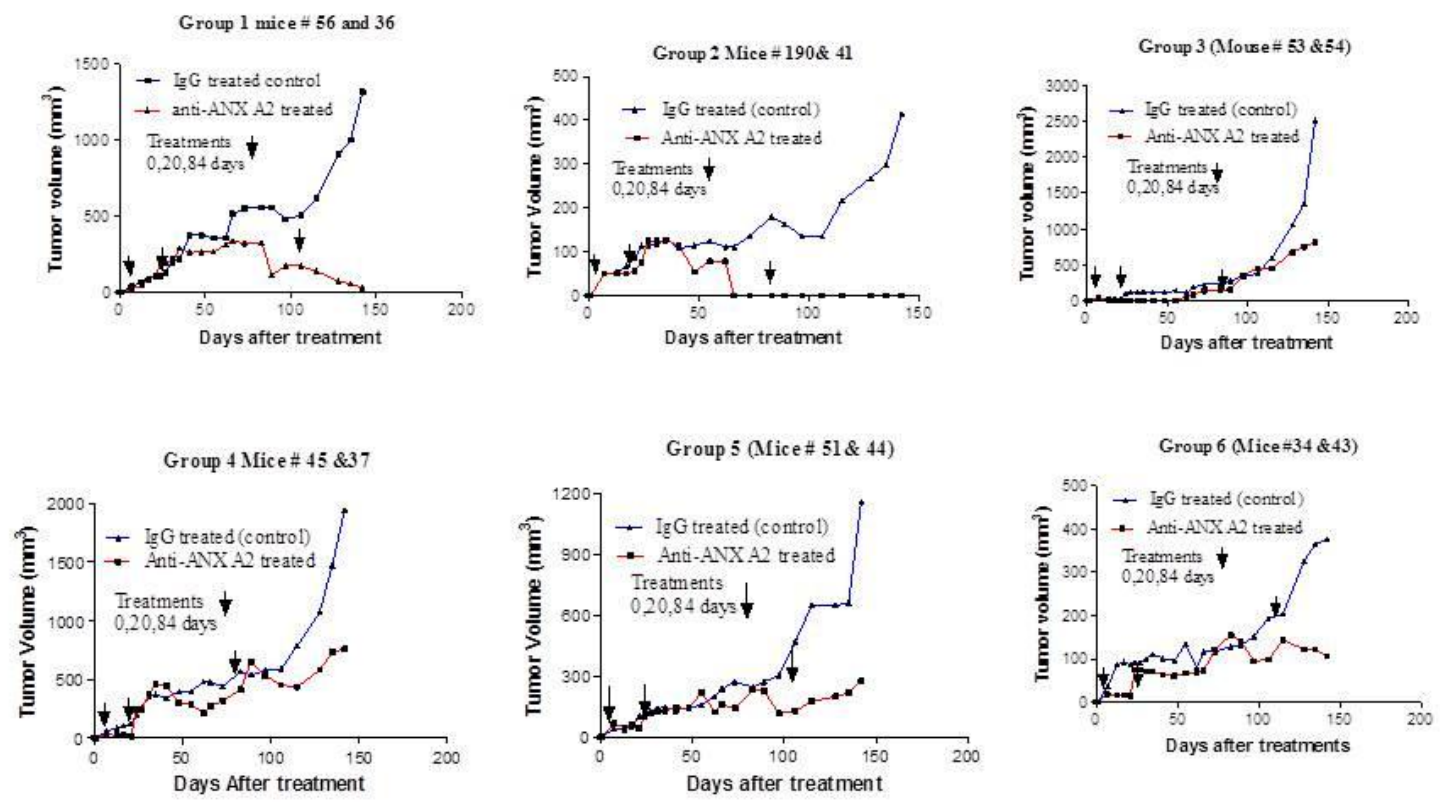
Fig.2

tPA expression
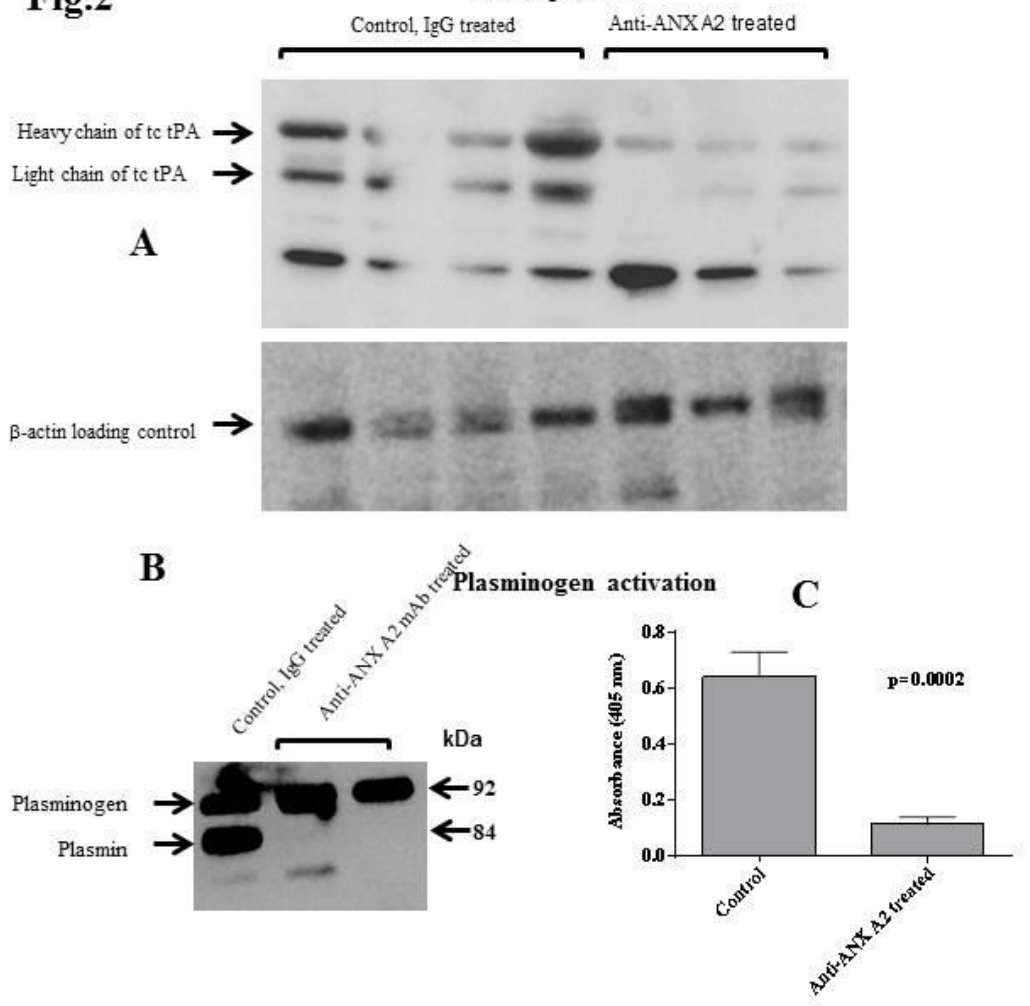
Fig.3
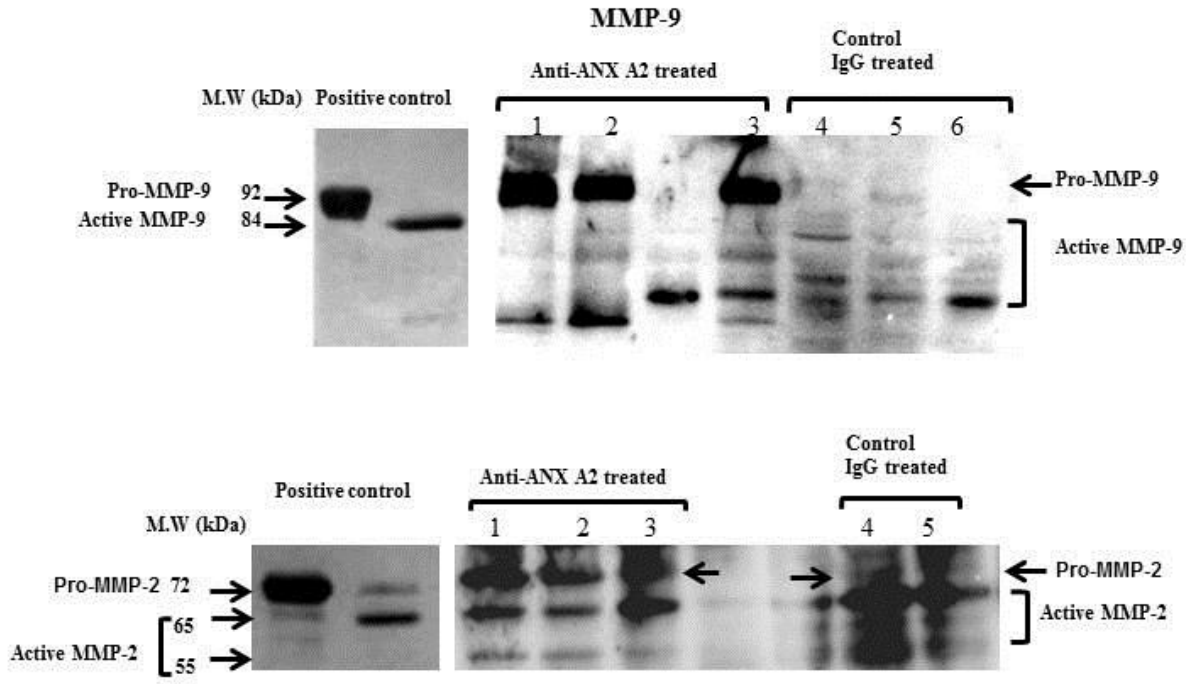


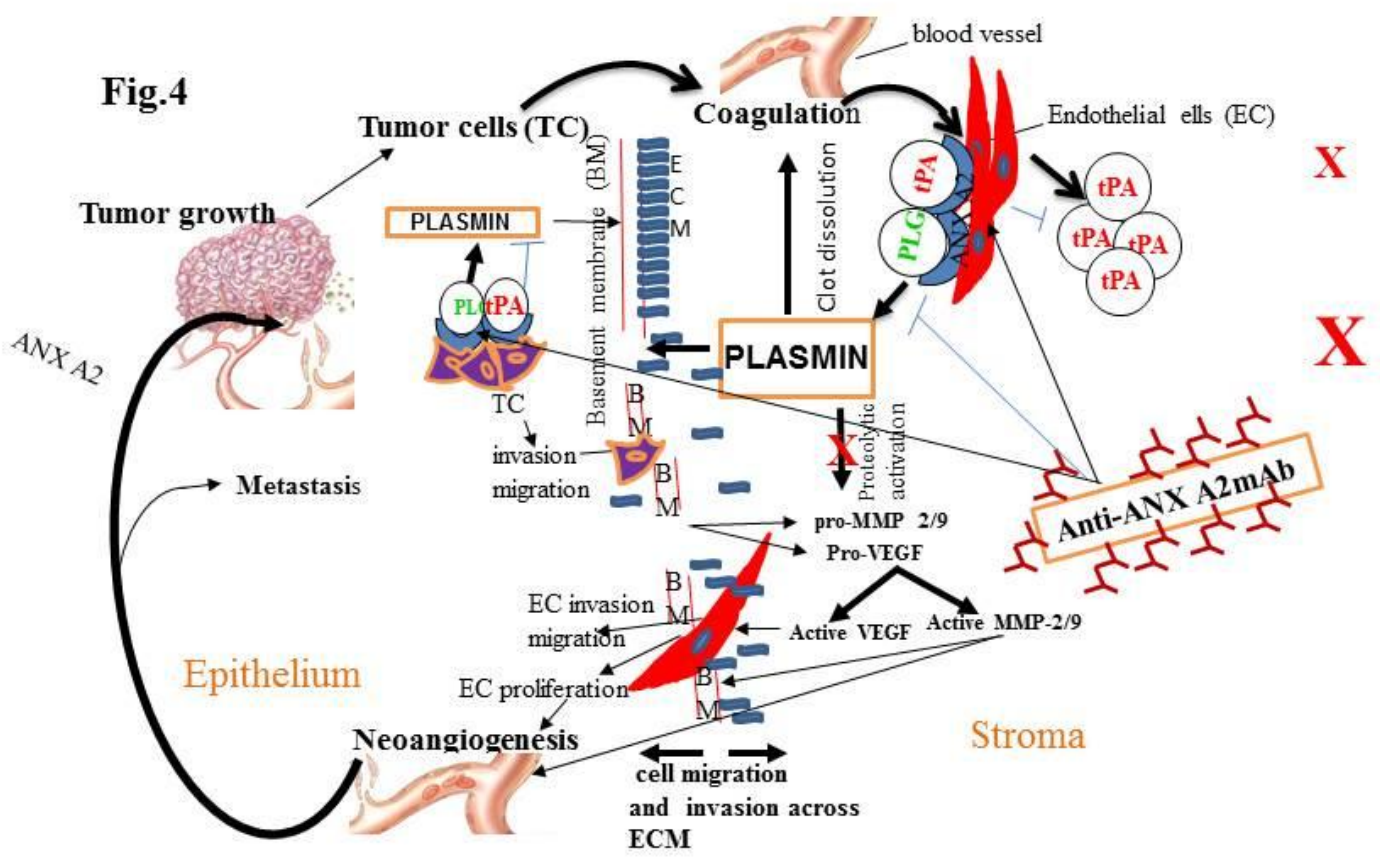




\section{Figure legends:}

\section{Fig.1}

\section{Long-term anti-breast tumor effects of anti-ANX A2 mAb therapy:}

Invasive MDA-MB231 (1X106) cells were implanted in immunodeficient mice (n=7/group). Tumor volume was determined (width ${ }^{2} \mathrm{x}$ length $\mathrm{x}$ 0.52) and when tumor volume was 50$100 \mathrm{~mm}^{3}$, mice received $10 \mathrm{mg} / \mathrm{kg}$ of anti-ANX A2 monoclonal antibody or isotype matched $\mathrm{IgG}$ injected intravenously (i.v). The Second and third treatments $(10 \mathrm{mg} / \mathrm{kg}$ ) were administered 20 and $84^{\text {th }}$ day after first treatment. During experimentation, one mouse died from experimental group; therefore, data are presented from 6 mice. The tumor growth patterns were monitored for 172 days after treatments (Panel A). Tumor growth was measured for the last time point and presented in a scattered graph (B). Tumor growth patterns of individual mice were determined after anti-ANX A2 treatments (D). Animal weights were measured during anti-ANX A2 mAb therapy, which demonstrated normal weight gain during treatment suggesting no major adverse $\operatorname{effect}(\mathrm{C})$.

\section{Fig.2}

\section{Anti-ANX A2 mAb therapy inhibited synthesis of tPA and activation of plasminogen in the tumor microenvironment:}

After termination of the experiment, tumor tissues were harvested, homogenized and centrifuged. Supernatants ( $20 \mu \mathrm{g}$ protein) were analyzed by immunoblot analysis using monoclonal anti-tPA antibody (panel A). Immunoblot results demonstrated that antibody therapy strongly inhibited conversion of active two chain (tc) tPA in the tumor microenvironment (panel A, arrows indicate active heavy and light chain of tc tPA). We also noticed a low molecular weight degradation band. Data presented are from individual mice and the experiment was repeated three times. To confirm inhibition of tPA, we assayed enzymatic activation of plasminogen in the tumor tissues. Results presented (C) demonstrated tumor tissues from control mice generated plasmin with high rate which was almost completely inhibited by anti-ANX A2 antibody therapy. Data shown are mean $+/$ - SD from 6 mice and the experiment was repeated three times. Reaction mixture $(10 \mu \mathrm{l})$ from enzymatic assay was separated on SDS-PAGE and immunoblotted with anti-plasminogen monoclonal antibody showed inhibition of plasminogen activation (panel B).

\section{Fig.3:}

Anti-ANX A2mAb therapy inhibited MMP-9/2 activation in the tumor microenvironment: Twenty microgram tumor homogenate protein was separated on SDS-PAGE and immunoblotted with MMP-9 (panel A) and MMP-2 (panel B) monoclonal antibodies. MMP-9 and MMP-2 pro and active form of enzymes used as positive controls. 
Our data showed that IgG (control) treated mice efficiently converted $92 \mathrm{kDa}$ MMP-9 proenzyme to active enzyme (panel A, lanes 4, 5, 6). This enzymatic activation of MMP-9 was significantly inhibited by anti-ANX A2mAb therapy (panel A, lanes 1, 2 and 3). Likewise, proMMP-2 was highly activated to active enzyme (panel B, lanes 4 and 5) in the tumor microenvironment, which was significantly inhibited by anti-ANX A2mAb therapy (Panel B, 1, 2 and3). Data presented here are from individual mice and the experiment was repeated three times.

Fig.4. Schematic model depicting potential ANX A2-mediated mechanism of breast tumor growth and its inhibition by ANX A2mAb: Tumor growth represents the pathology of crosstalk among multiple cells in stromal, epithelial and vascular compartments. Tumor growth is preceded by procoagulant activity induced by tumor cells (TC) in the vascular compartment. Vascular endothelial cells (ECs) are first responders against blood coagulation/vascular injury. During EC injury /blood clot triggers a complex biochemical cascade to neutralize coagulation/repair injury. In the first step to dissolve blood clot or repair injury 1) ECs secrete tPA concurrent with induction of ANX A2 expression, which in turn activate plasminogen to plasmin, a major fibrinolytic pathway. Plasmin dissolves blood clots and also initiates tissue remodeling events to repair injury by degradation of the ECM and BM. This allows EC and TC invasion and migration across the tissue compartments. During ECM degradation and tissue remodeling events matrix-bound inactive Pro-VEGF and Pro-MMP-9/2 are released in the milieu to help with tissue remodeling events/repair the injury. These pro-molecules require proteolytic activity of plasmin for activation to exert their biological functions. Thus, activated MMP-9/2 provide feedback cascade to accelerate ECM and BM degradation and activated VEGF reprogram migrating ECs for proliferation and neoangiogenesis in the tumor microenvironment. Collectively, activation of these proteolytic pathways triggers neoangiogenesis which in turn facilitates tumor growth and invasion. Additionally, during vascular remodeling events, TC gain access into blood circulation and develop new tumor colonies in the distant organs leading to metastasis. Anti-ANX A2mAb binding to TC/EC surface ANX A2 inhibits biochemical activation of plasminogen thereby disrupt the biochemical activation of MMP-9/2 and VEGF leading to blockade of ECM,BM degradation, neoangiogenesis, TC/EC invasion, migration, and eventually inhibit tumor growth. 
Table-1

\begin{tabular}{|c|c|c|c|c|c|c|c|}
\hline $\begin{array}{l}\text { Human breast } \\
\text { cancer cell line }\end{array}$ & $\mathbf{n}$ & $\begin{array}{l}\text { Treatment } \\
\text { (Control) }\end{array}$ & $\mathbf{n}$ & $\begin{array}{l}\text { Treatment } \\
\text { (Experimental) }\end{array}$ & $\begin{array}{c}\text { Dose } \\
(\mathrm{mg} / \mathrm{kg})\end{array}$ & \multicolumn{2}{|c|}{$\begin{array}{l}\text { Days } \\
\text { (treatment injected) }\end{array}$} \\
\hline MDA-MB231 & 7 & Isotype matched IgG & 7 & \multicolumn{2}{|c|}{ Anti-ANX A2 mAb } & 10 & 0 \\
\hline MDA-MB231 & & Isotype matched $\mathrm{IgG}$ & & \multicolumn{2}{|c|}{ Anti-ANX A2 mAb } & 10 & $20^{\text {th }}$ \\
\hline MDA-MB231 & & Isotype matched IgG & & \multicolumn{2}{|c|}{ Anti-ANX A2 mAb } & 10 & $84^{\text {th }}$ \\
\hline
\end{tabular}

